Check for updates

Cite this: RSC Adv., 2018, 8, 13226

Received 15th February 2018 Accepted 21st March 2018

DOI: $10.1039 / c 8 r a 01449 c$

rsc.li/rsc-advances

\section{Formation of bicyclic polycyclic aromatic hydrocarbons (PAHs) from the reaction of a phenyl radical with cis-3-penten-1-yne $\uparrow$}

\author{
Mingrui Wei, ${ }^{a}$ Tingting Zhang, (iD a Xianfeng Chen, ${ }^{b}$ Fuwu Yan, ${ }^{a}$ Guanlun Guo (DD *a \\ and Dongju Zhang*c
}

The formation of polycyclic aromatic hydrocarbons (PAHs) on the $\mathrm{C}_{11} \mathrm{H}_{11}$ potential energy surface involved in the reactions of a phenyl radical $\left(\mathrm{C}_{6} \mathrm{H}_{5}\right)$ with cis-3-penten-1-yne (cis- $\mathrm{C}^{1} \mathrm{H} \equiv \mathrm{C}^{2}-\mathrm{C}^{3} \mathrm{H}=\mathrm{C}^{4} \mathrm{H}-\mathrm{C}^{5} \mathrm{H}_{3}$, referred to as $\left.\mathrm{C}_{5} \mathrm{H}_{6}\right)$ and its three radicals $\left(\mathrm{CH} \equiv \mathrm{C}-\dot{\mathrm{C}}=\mathrm{CH}-\mathrm{CH}_{3}, \mathrm{CH} \equiv \mathrm{C}-\mathrm{CH}=\dot{\mathrm{C}}-\mathrm{CH}_{3}\right.$, and cis- $\mathrm{CH} \equiv \mathrm{C}-$ $\mathrm{CH}=\mathrm{CH}-\dot{\mathrm{C}} \mathrm{H}_{2}$, referred to as the $\mathrm{C}^{3}-, \mathrm{C}^{4}-$, and $\mathrm{C}^{5}$-radicals with the same chemical components, $\mathrm{C}_{5} \mathrm{H}_{5}$ ) assisted by $\mathrm{H}$ atoms is investigated by performing combined density functional theory (DFT) and ab initio calculations. Five potential pathways for the formation of PAHs have been explored in detail: Pathways III correspond to the reaction of $\mathrm{C}_{6} \mathrm{H}_{5}$ with $\mathrm{C}_{5} \mathrm{H}_{6}$ at the $\mathrm{C}^{1}$ and $\mathrm{C}^{2}$ position, and Pathways III-V involve the reaction of $\mathrm{C}_{6} \mathrm{H}_{5}$ with the $\mathrm{C}^{3}-, \mathrm{C}^{4}$-, and $\mathrm{C}^{5}$-radicals with the assistance of $\mathrm{H}$ atoms. The initial association of $\mathrm{C}_{6} \mathrm{H}_{5}$ with $\mathrm{C}_{5} \mathrm{H}_{6}$ or $\mathrm{C}_{5} \mathrm{H}_{5}$ is found to be highly exothermic with only minor barriers (1.4$7.1 \mathrm{kcal} \mathrm{mol}^{-1}$ ), which provides a large driving force for the formation of PAHs. The hydrogen atom is beneficial for the ring enlargement and ring formation processes. The present calculations predict 9 potential PAHs, six (CS6, CS10, CS13, CS26, CS28 and CS29) of which are indicated to be energetically more favorable along Pathways I, III, IV and V at low temperature. The calculated barriers for the formation of these PAHs are around $19.2-38.0 \mathrm{kcal} \mathrm{mol}^{-1}$. All PAHs products could be formed at flame temperature, for the medium barriers are easily overcome in various flame conditions. The theoretical results supplement the PAH formation pathway and provide help to understand PAH growth mechanism.

\section{Introduction}

Polycyclic aromatic hydrocarbons (PAHs) are commonly believed to mainly come from the incomplete combustion of fuels. Due to their toxicity and carcinogenic properties, ${ }^{\mathbf{1 , 2}}$ the study of the formation mechanism of PAHs has become a major subject in the fields of combustion and environmental science during the past decades. ${ }^{3}$ The most widely accepted theory for $\mathrm{PAH}$ formation and growth involves a hydrogen-abstractionacetylene-addition (HACA) mechanism, ${ }^{4-6}$ which has been extensively studied by both experimentalists and theorists and was popularly used in combustion models. ${ }^{7-12}$ However, the HACA mechanism was found to underestimate the concentrations of PAHs and soot when compared with the experimental results. ${ }^{12,13}$ Further experimentalists found that many non-

${ }^{a}$ Hubei Key Laboratory of Advanced Technology for Automotive Components, Hubei Collaborative Innovation Center for Automotive Components Technology, Wuhan University of Technology, Wuhan 430070, PR China. E-mail: glguo@whut.edu.cn

${ }^{b}$ School of Resources and Environmental Engineering, Wuhan University of Technology, Wuhan 430070, China

${ }^{c}$ Key Lab of Colloid and Interface Chemistry, Ministry of Education, School of Chemistry and Chemical Engineering, Shandong University, Jinan 250000, PR China $\dagger$ Electronic supplementary information (ESI) available. See DOI: 10.1039/c8ra01449c acetylene type organic compounds, such as $\mathrm{CH}_{3}, \mathrm{C}_{3} \mathrm{H}_{3}, \mathrm{C}_{3} \mathrm{H}_{4}$, $\mathrm{C}_{3} \mathrm{H}_{6}, \mathrm{C}_{4} \mathrm{H}_{2}, \mathrm{C}_{4} \mathrm{H}_{4}, \mathrm{C}_{4} \mathrm{H}_{6}$ and $\mathrm{C}_{5} \mathrm{H}_{8}$ (ref. 14 and15) also contributed to $\mathrm{PAH}$ growth in various flame configurations. Therefore, the $\mathrm{PAH}$ formation from non-acetylene compounds has

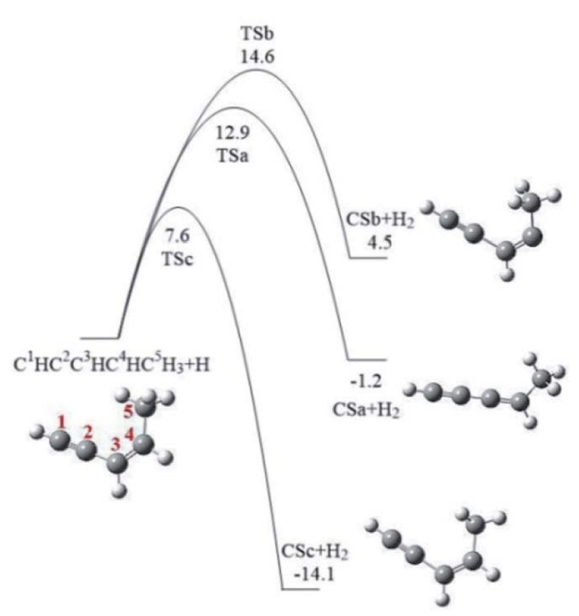

Fig. 1 Relative energy surfaces for the formation of the three $\mathrm{C}_{5} \mathrm{H}_{5}$ radicals of cis-3-penten-1-yne via the $\mathrm{H}$-abstraction reactions at the $\mathrm{C}^{3}, \mathrm{C}^{4}$ and $\mathrm{C}^{5}$ positions by an external $\mathrm{H}$ atom. Relative energies are in $\mathrm{kcal} \mathrm{mol}^{-1}$. 


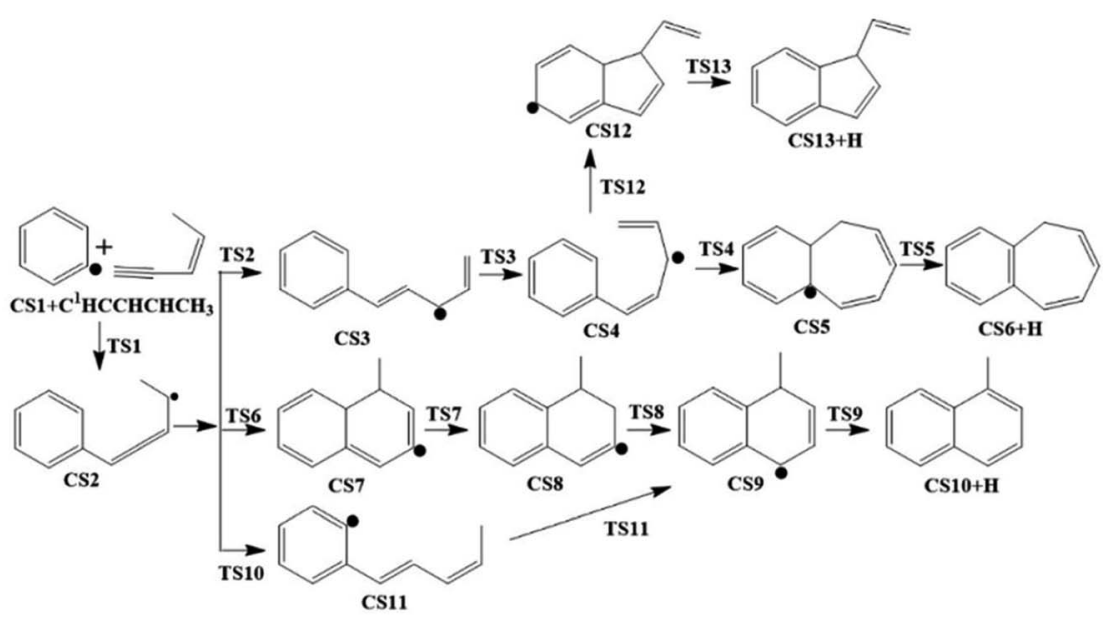

Fig. 2 Pathway l: the reaction of phenyl radical with cis-3-penten-1-yne at the $C^{1}$ position.

attracted remarkable attention. ${ }^{16-26}$ Furthermore, the introduction of reaction mechanism of odd-carbon chemistries as additions, especially $\mathrm{C}_{3}$ and $\mathrm{C}_{5}$ species, into HACA mechanism were found to reproduce the synergistic effect of some mixing fuels on PAH and soot formations. ${ }^{27-35}$ Hence, the roles of $\mathrm{C}_{3}$ and $c y c l o-\mathrm{C}_{5}$ species as additions on the $\mathrm{PAH}$ growth have be studied experimentally and theoretically. ${ }^{17-19,36-40}$ Different from cyclo- $\mathrm{C}_{5}$ species, the linear $\mathrm{C}_{5}$ species draw little attentions on the PAHs formation mechanism studies, except that reactions of $\mathrm{C}_{5} \mathrm{H}_{3}$ and $\mathrm{C}_{5} \mathrm{H}_{5}$ with $\mathrm{CH}_{3}$ have been postulated as possible routes of benzene formation. ${ }^{11-13}$ And, isoprene $\left(\mathrm{C}_{5} \mathrm{H}_{8}\right)$, the methyl-substituted 1,3-butadiene, was found to react with phenyl radical barrier-lessly. ${ }^{26,41}$ However, Hansen et al. ${ }^{42}$ identified the isomers of linear $\mathrm{C}_{5}$ chemicals, and found that cis-3penten-1-yne $\left(\mathrm{CH} \equiv \mathrm{C}-\mathrm{CH}=\mathrm{CH}-\mathrm{CH}_{3}\right)$ was the most stable linear $\mathrm{C}_{5} \mathrm{H}_{6}$, and $\mathrm{CH} \equiv \mathrm{C}-\mathrm{CH}=\mathrm{CH}-\mathrm{CH}_{2}$ radical the most stable linear $\mathrm{C}_{5} \mathrm{H}_{5}$ radical. Structurally, $\mathrm{CH} \equiv \mathrm{C}-\mathrm{CH}=\mathrm{CH}-\mathrm{CH}_{3}$ is the methylsubstituted product of vinylacetylene $\left(\mathrm{CHCCHCH}_{2}\right)$, which can form naphthalene via the bimolecular reactions with para-tolyl and phenyl radicals without entrance barriers under single collision conditions. ${ }^{21-23}$ Thus, it is meaningful to investigate the reaction of phenyl radical with $\mathrm{CHCCHCHCH}_{3}$.

The main objective of this work is to explore the formation of potential PAHs within 4-, 5-, 6- and 7-membered rings on $\mathrm{C}_{11} \mathrm{H}_{11}$ potential energy surface (PES) from phenyl radical $\left(\mathrm{C}_{6} \mathrm{H}_{5}\right)$ with cis-3-penten-1-yne and its radicals. These 4-, 5- and 7-membered PAHs were all detected from vehicle emissions ${ }^{43,44}$ and confirmed as major contributors to soot formation in the postflame region. ${ }^{45-47}$ By performing combined density functional theory (DFT) and ab initio calculations, we discuss the influences of reactive sites and methyl group of $\mathrm{CHCCHCHCH}_{3}$ on the formation of bicyclic PAHs, and the roles of hydrogen atoms in ring formation and ring enlargement steps.

\section{Methods}

The molecular structures involved in the reactions under study were optimized on $\mathrm{C}_{11} \mathrm{H}_{11}$ PES by using the hybrid B3LYP functional with the $6-311++\mathrm{G}(\mathrm{d}, \mathrm{p})$ basis set. ${ }^{48-50}$ The vibrational frequency calculations were performed at the same level to

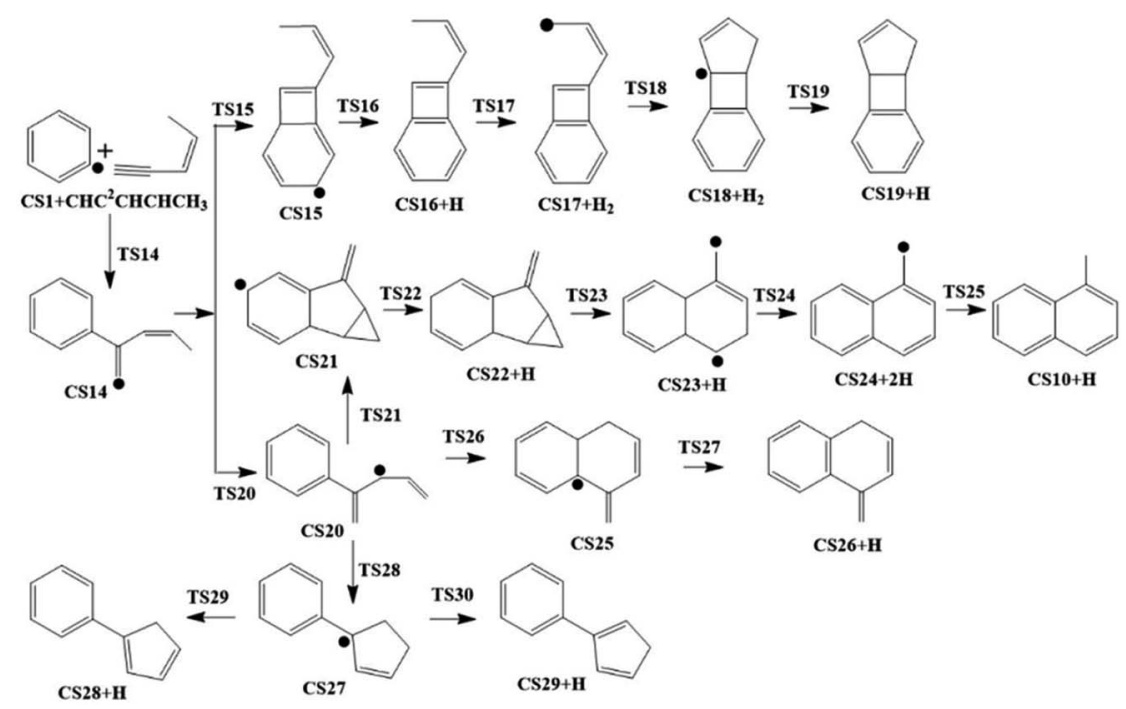

Fig. 3 Pathway II: the reaction of phenyl radical with cis-3-penten-1-yne at the $C^{2}$ position. 


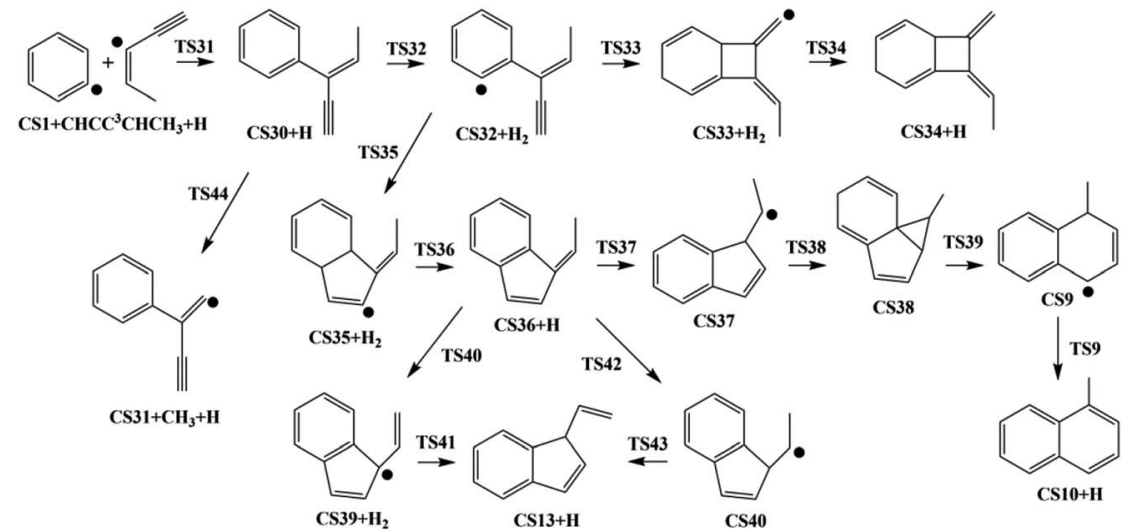

Fig. 4 Pathway III: the reaction of phenyl radical with the $C^{3}$-radical of cis-3-penten-1-yne.

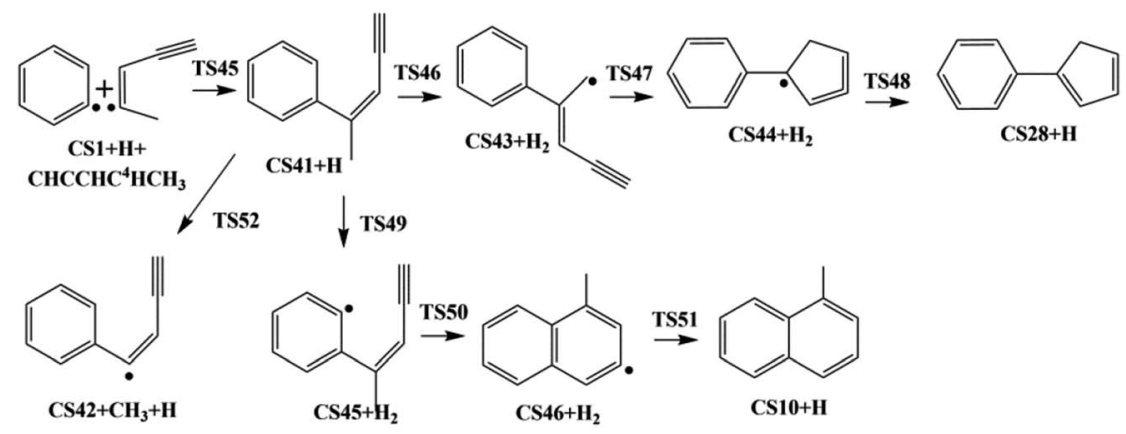

Fig. 5 Pathway IV: the reaction of phenyl radical with the $C^{4}$-radical of cis-3-penten-1-yne.

identify the optimized structures as local minimum or firstpoint saddle points and to provide their zero-point vibrational energies (ZPE). The intrinsic reaction coordinate calculations were implemented to ensure that the transition states connect to the relevant reactants and products correctly. The final single-point energies of all species were gained using the

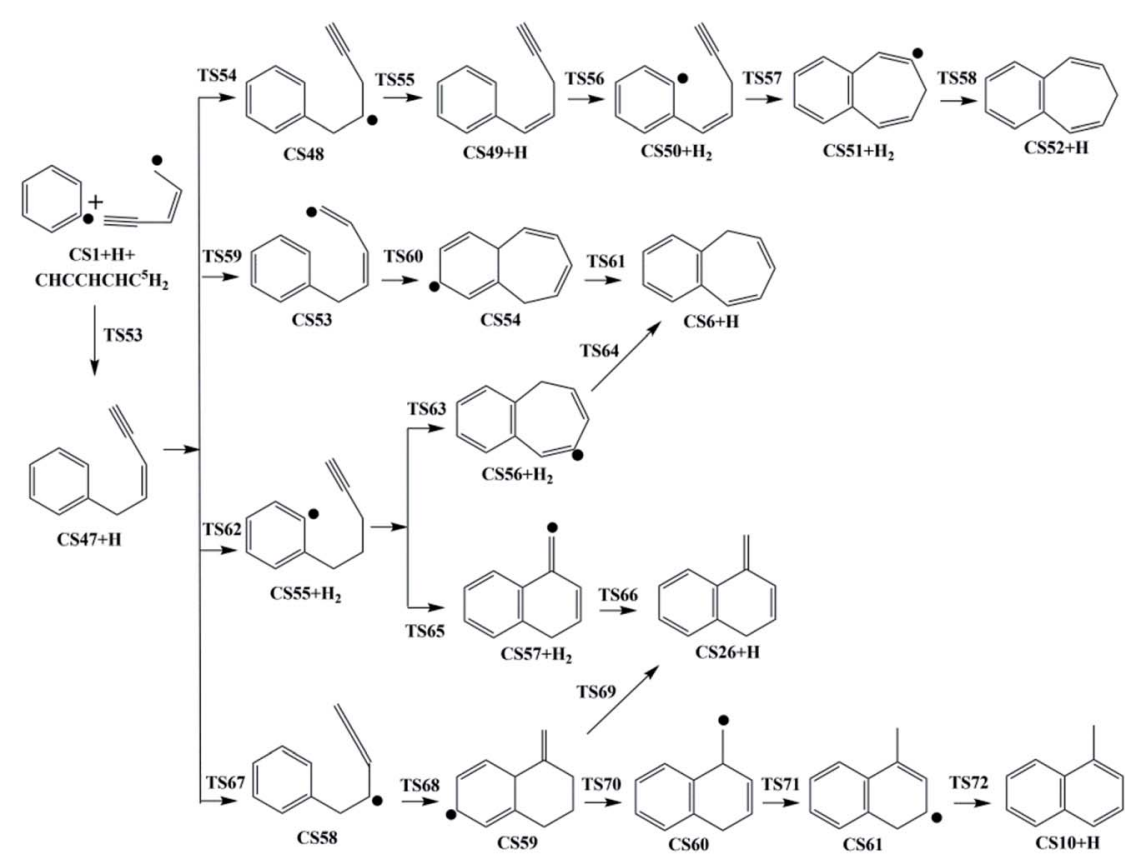

Fig. 6 Pathway V: the reaction of phenyl radical with the $C^{5}$-radical of cis-3-penten-1-yne. 


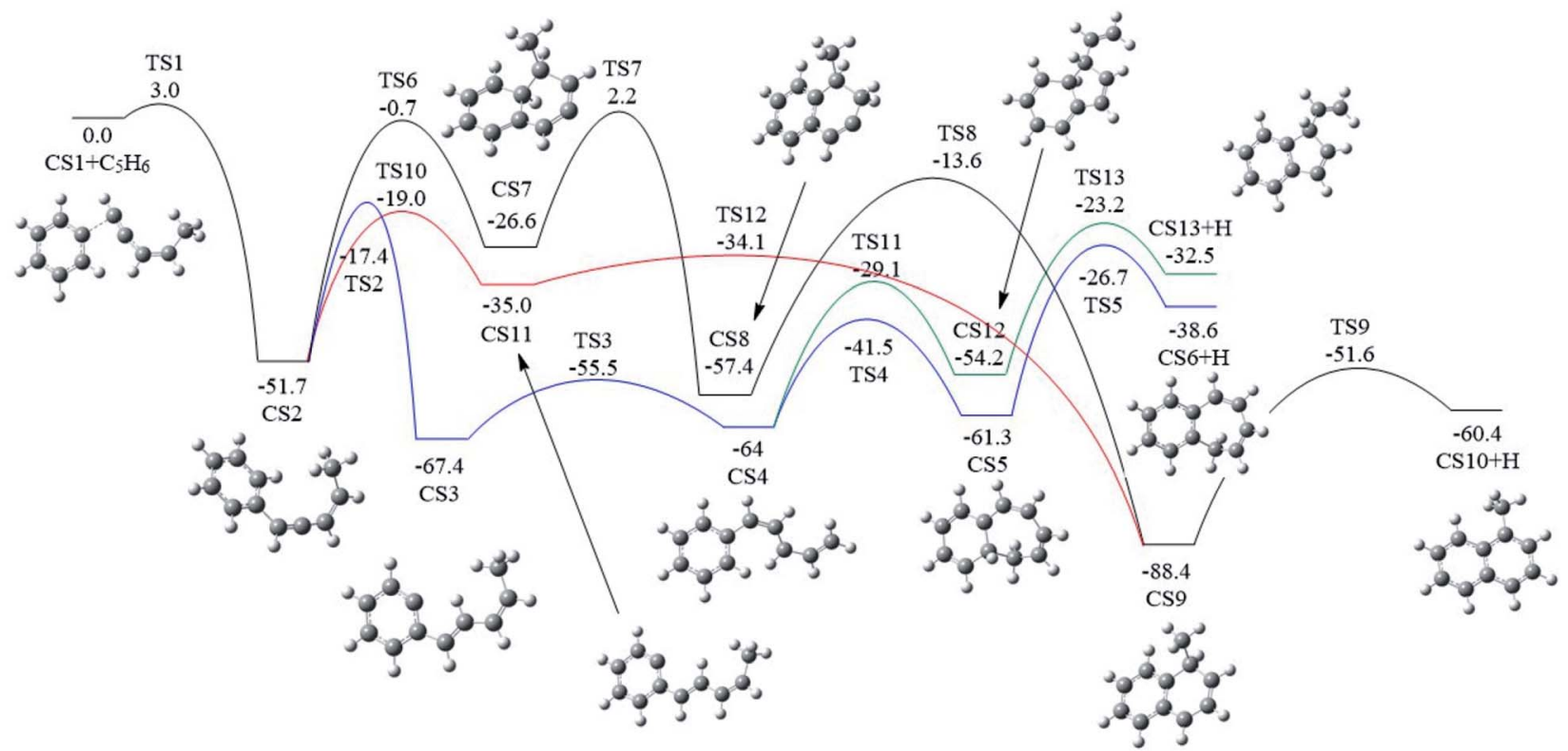

Fig. 7 Calculated potential energy surface of Pathway I started from the association of $\mathrm{C}_{6} \mathrm{H}_{5}$ to the $\mathrm{C}^{1}$ position of $\mathrm{C}^{1} \mathrm{HC}^{2} \mathrm{C}^{3} \mathrm{HC} \mathrm{C}^{4} \mathrm{HC}^{5} \mathrm{H}_{3}$. Relative energies are in $\mathrm{kcal} \mathrm{mol}^{-1}$.

G3(MP2,CC) method, ${ }^{23,25}$ which is expected to generate relative energies of various species within the accuracy of 1$2 \mathrm{kcal} \mathrm{mol}{ }^{-1},{ }^{51}$ and extensively used to study PAH growth mechanism..$^{\mathbf{8}, \mathbf{9}, \mathbf{1 8 2} 2 \mathbf{2 3}}$ The majority of the intermediate species and transition structures found in this study were either closed shell singlets or open shell doubles. The diradical species were found by using triplet spin multiplicity, and the calculations of diradical species contain negligible spin contamination. A high spin contamination can affect the geometry and energy of the molecule. ${ }^{52}$ As a check for the presence of spin contamination, $a b$ initio calculations give the expectation value of the total spin $\left\langle S^{2}\right\rangle$. If there is no spin contamination, $\left\langle S^{2}\right\rangle$ should equal $s(s+1)$,

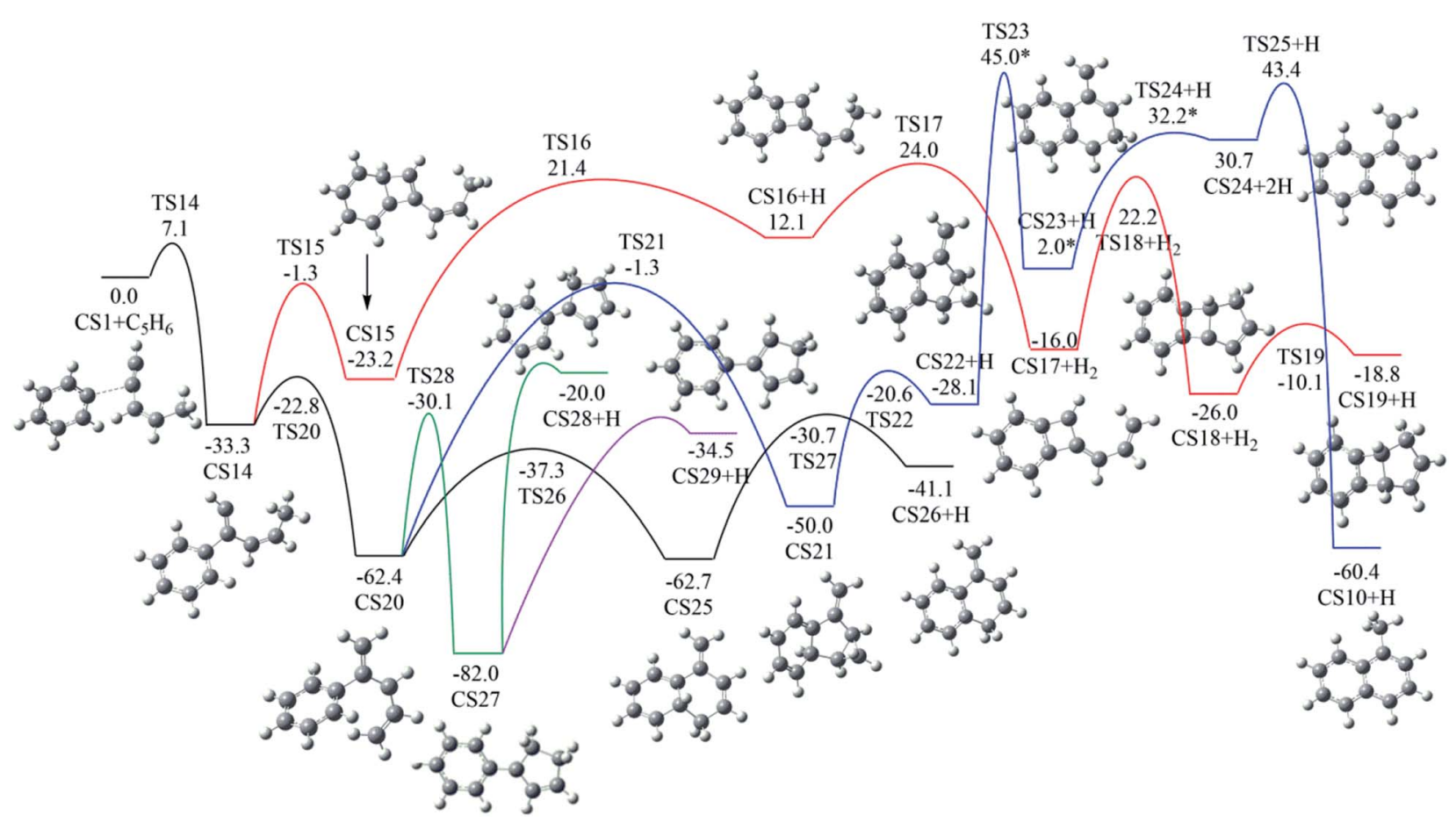

Fig. 8 Calculated potential energy surface of Pathway II started from the association of $\mathrm{C}_{6} \mathrm{H}_{5}$ to the $\mathrm{C}^{2}$ position of $\mathrm{C}^{1} \mathrm{HC}^{2} \mathrm{C}^{3} \mathrm{HC}{ }^{4} \mathrm{HC} C^{5} \mathrm{H}_{3}$. Relative energies are in $\mathrm{kcal} \mathrm{mol}^{-1}$. 


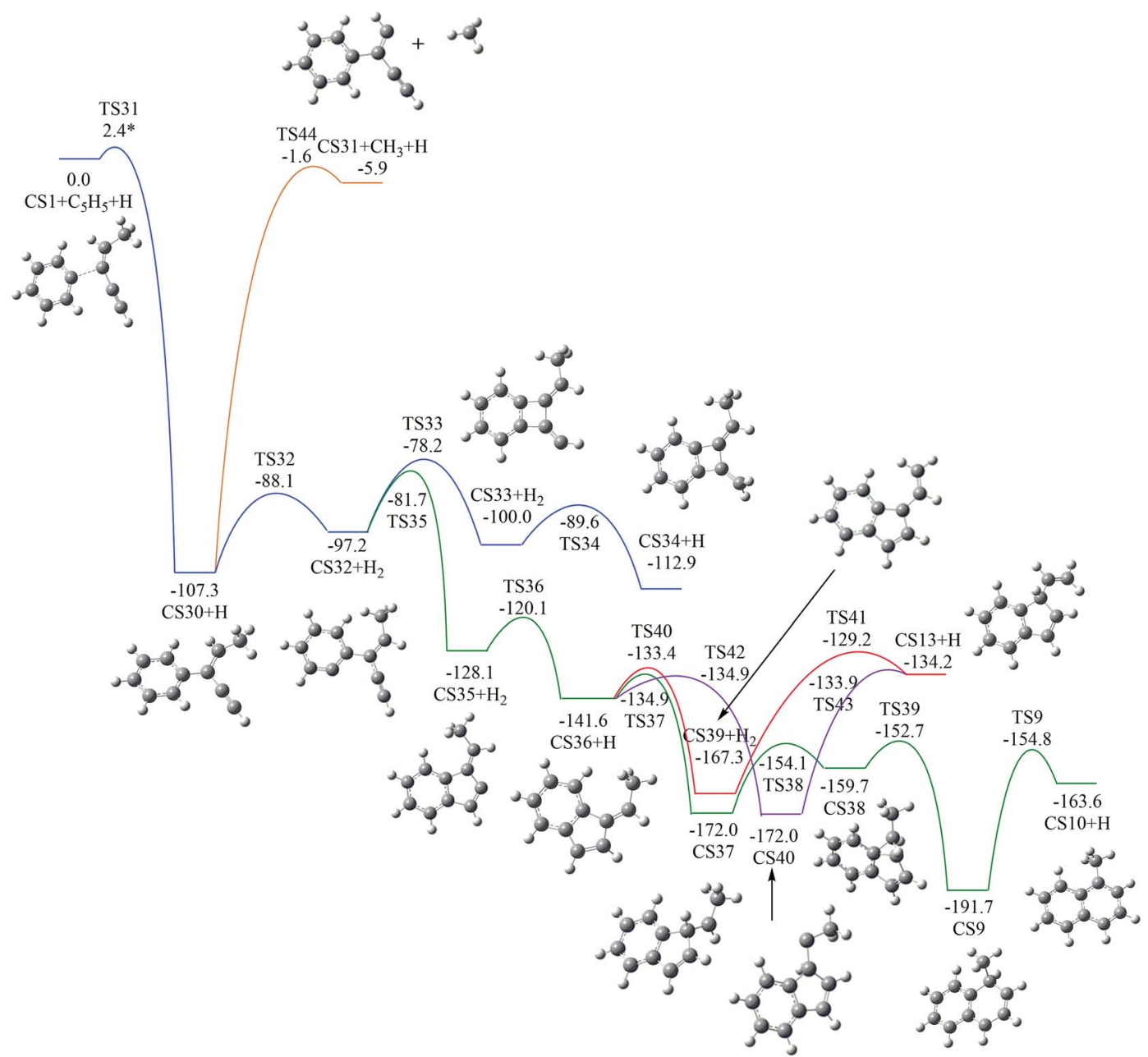

Fig. 9 Calculated potential energy surface of Pathway III started with the reaction of $\mathrm{C}_{6} \mathrm{H}_{5}$ to the $\mathrm{C}^{3}$ position of $\mathrm{C}^{1} \mathrm{HC} \mathrm{C}^{2} \mathrm{C}^{3} \mathrm{C}^{4} \mathrm{HC} \mathrm{C}^{5} \mathrm{H}_{3}$. Relative energies are in $\mathrm{kcal} \mathrm{mol}^{-1}$.

where $s$ equals $1 / 2$ times the number of unpaired electrons. One rule of thumb, which was derived from experience with organic molecule calculations, is that the spin contamination is negligible if the value of $\left\langle S^{2}\right\rangle$ differs from $s(s+1)$ by less than $10 \%$. In addition, spin contamination has little effect on DFT, CC and CI calculations. ${ }^{52,53} \mathrm{All}\left\langle S^{2}\right\rangle$ values of chemical species or transition states with 2 unpaired electrons in this study were shown in ESI. $\dagger$ Asterisks were added to energies corresponding to diradical species with spin contamination. The G3(MP2,CC) energies are calculated according to the following equation:

$$
\begin{aligned}
E[\mathrm{G} 3(\mathrm{MP} 2, \mathrm{CC})] & =E[\mathrm{CCSD} / 6-311++(\mathrm{d}, \mathrm{p})]+\Delta E(\mathrm{MP} 2) \\
& +\Delta E(\mathrm{SO})+\Delta E(\mathrm{HLC})+E(\mathrm{ZPE})
\end{aligned}
$$

where $\Delta E(\mathrm{MP} 2)=E[\mathrm{MP} 2 / 6-311 \mathrm{G}++(3 \mathrm{df}, 2 \mathrm{p})]-E[\mathrm{MP} 2 / 6-$ $311 \mathrm{G}++(\mathrm{d}, \mathrm{p})]$ is the basis set correction. $\Delta E(\mathrm{SO})$ is the spin-orbit correction, included for atomic species only. Higher level correction (HLC) for molecules is $\Delta E(\mathrm{HLC})=-A n_{\mathrm{b}}-B\left(n_{\mathrm{a}}-n_{\mathrm{b}}\right)$ with $A=9.279$ mhartrees and $B=4.471$ mhartrees, and for atoms is $\Delta E($ HLC $)=-C n_{\mathrm{b}}-D\left(n_{\mathrm{a}}-n_{\mathrm{b}}\right)$ with $C=9.345$ mhartrees and $D=2.021$ mhartrees. The $n_{\mathrm{a}}$ and $n_{\mathrm{b}}$ are the number of a and $\mathrm{b}$ valence electrons, respectively. All calculations were performed using the Gaussian 09 package. ${ }^{54}$

\section{Results and discussion}

cis-3-Penten-1-yne with one $\mathrm{C}-\mathrm{C}$ triple bond, one $\mathrm{C}-\mathrm{C}$ double bond, and two $\mathrm{C}-\mathrm{C}$ single bonds, contains five chemically unequivalent carbon atoms, marked as $\mathrm{C}^{1}, \mathrm{C}^{2}, \mathrm{C}^{3}, \mathrm{C}^{4}$ and $\mathrm{C}^{5}$ (Fig. 1), and its reaction with phenyl radical may initially occur at any one of these carbon atoms, corresponding to five possible pathways shown in Fig. 2-6. It is known that a vinyl-type group can conjugate to the $-\mathrm{C} \equiv \mathrm{CH}$ group to form a resonantly stabilized free radical (RSFR) intermediate, which was confirmed to play important role in PAHs formation. ${ }^{26,55}$ Thus, phenyl radical $\left(\mathrm{C}_{6} \mathrm{H}_{5}\right)$, a typical vinyl-type group, can directly conjugate to $\mathrm{C}^{1}$ or $\mathrm{C}^{2}$ position of $c i$-3-penten-1-yne via Pathway I or Pathway II. Alternatively, it can also react with three $\mathrm{C}_{5} \mathrm{H}_{5}$ radicals of cis-3-penten-1-yne with the single electron respectively located at $\mathrm{C}^{3}, \mathrm{C}^{4}$ and $\mathrm{C}^{5}$ positions, via Pathways III-V. All pathways were on $\mathrm{C}_{11} \mathrm{H}_{11}$ PES, and only reactions lead to the PAHs products were considered in this study. Fig. 1 shows the 
formation of these three radicals, denoted as CSa, CSb, and CSc from cis-3-penten-1-yne via the $\mathrm{H}$-abstraction reaction by an external $\mathrm{H}$ atom. It is found that the barriers involved in the $\mathrm{H}$ abstraction reactions are 12.9, 14.6 and $7.6 \mathrm{kcal} \mathrm{mol}^{-1}$, respectively, implying that $\mathrm{CSc}$ is easier to be produced than $\mathrm{CSa}$ and $\mathrm{CSb}$.

The present work studied five possible pathways, as schematically shown in Fig. 2-6. The resulting PAHs include benzocycloheptatriene (CS6), 1-methylnaphthalene (CS10), 1-vinyl$1 H$-indene (CS13), 3a,7b-dihydro-1H-cyclopenta[3,4]cyclobuta [1,2]benzene (CS19), 1-methylene-1,4-dihydronaphthalene (CS26), cyclopenta-1,3-dien-1-ylbenzene (CS28), cyclopenta-1,4dien-1-ylbenzene (CS29), (Z)-7-ethylidene-8-methylenebicyclo [4.2.0]octa-1(6),2,4-triene (CS34), and 7H-Benzo[7]annulene (CS52). The following discussion shows the mechanism details for the formation of these PAHs.

\subsection{Pathway I}

As shown in Fig. 2 and 7, there are four potential channels for the reaction of $\mathrm{C}_{6} \mathrm{H}_{5}$ with $\mathrm{C}^{1} \mathrm{HCCHCHCH}_{3}$ to the $\mathrm{C}^{1}$ position, resulting in three PAHs, CS6, CS10, and CS13. The initial association of $\mathrm{C}_{6} \mathrm{H}_{5}$ to the $\mathrm{C}^{1}$ position of $\mathrm{C}^{1} \mathrm{HCCHCHCH}_{3}$ results in the formation of $\mathrm{CS} 2$. This process is found to be a thermodynamically and kinetically favorable process, highly exothermic (51.7 $\mathrm{kcal}^{\mathrm{mol}^{-1}}$ ) with a very small barrier (3.0 kcal mol $\mathrm{m}^{-1}$, providing a large driving force for the subsequent formation of PAHs. The result is comparable with that for the reaction of $\mathrm{C}_{6} \mathrm{H}_{5}$ with $\mathrm{C}_{2} \mathrm{H}_{2}$ with a barrier of $\sim 6 \mathrm{kcal} \mathrm{mol}^{-1}$ and a reaction energy of $39 \mathrm{kcal} \mathrm{mol}{ }^{-1} \cdot{ }^{56}$ Once formed, CS2 can evolves into PAHs via different channels. The blue one, CS1 + $\mathrm{C}_{5} \mathrm{H}_{6} \rightarrow \mathrm{CS} 2 \rightarrow \mathrm{CS} 3 \rightarrow \mathrm{CS} 4 \rightarrow \mathrm{CS} 5 \rightarrow \mathrm{CS} 6$, involves $\mathrm{H}-$ migration, cis-trans conversion, ring-closure, and $\mathrm{H}$ dissociation steps, leading to the formation of benzocycloheptatriene (CS6). The barriers of these four elementary steps are $34.3,11.9,22.5$ and $34.6 \mathrm{kcal} \mathrm{mol}^{-1}$, respectively. Note that CS4, instead of evolving into CS6 along the bule channel, can evolve into a relative more stable PAH, CS13 alone the green sub-pathway in Fig. 7, CS4 $\rightarrow$ CS12 $\rightarrow$ CS13, via ring-closure and $\mathrm{H}$-dissociation steps. The ring-closure reaction occurs at $\mathrm{C}^{3}$ position with a barrier of $34.9 \mathrm{kcal} \mathrm{mol}^{-1}$, leading to CS12, a 5-membered bicyclo-PAH, which then dissociates into CS13 + $\mathrm{H}$ with a barrier of $31.0 \mathrm{kcal} \mathrm{mol}^{-1}$.

The black channel in Fig. 7, CS2 $\rightarrow$ CS7 $\rightarrow$ CS8 $\rightarrow$ CS9 $\rightarrow$ CS10, shows the formation of 1-methylnaphthalene (CS10), involving ring closure, twice $\mathrm{H}$-migration, and $\mathrm{H}$-dissociation steps via TS6-TS9. The barriers of these four steps are calculated to be 51.0, 28.8, 43.8 and $36.8 \mathrm{kcal} \mathrm{mol}^{-1}$, respectively. Clearly, such a channel is energetically very unfavorable for the formation of CS10. Alternatively, a relatively more viable channel has been identified, as shown by the red line in Fig. 7, i.e. $\mathrm{CS} 2 \rightarrow \mathrm{CS} 11 \rightarrow \mathrm{CS} 9 \rightarrow \mathrm{CS} 10$. Along this channel, CS2 is converted to CS10, undergoing $\mathrm{H}$-migration, ring closure, and $\mathrm{H}$-dissociation steps. The barriers involved in these three steps are $32.7,0.9$ and $36.8 \mathrm{kcal} \mathrm{mol}^{-1}$, respectively.

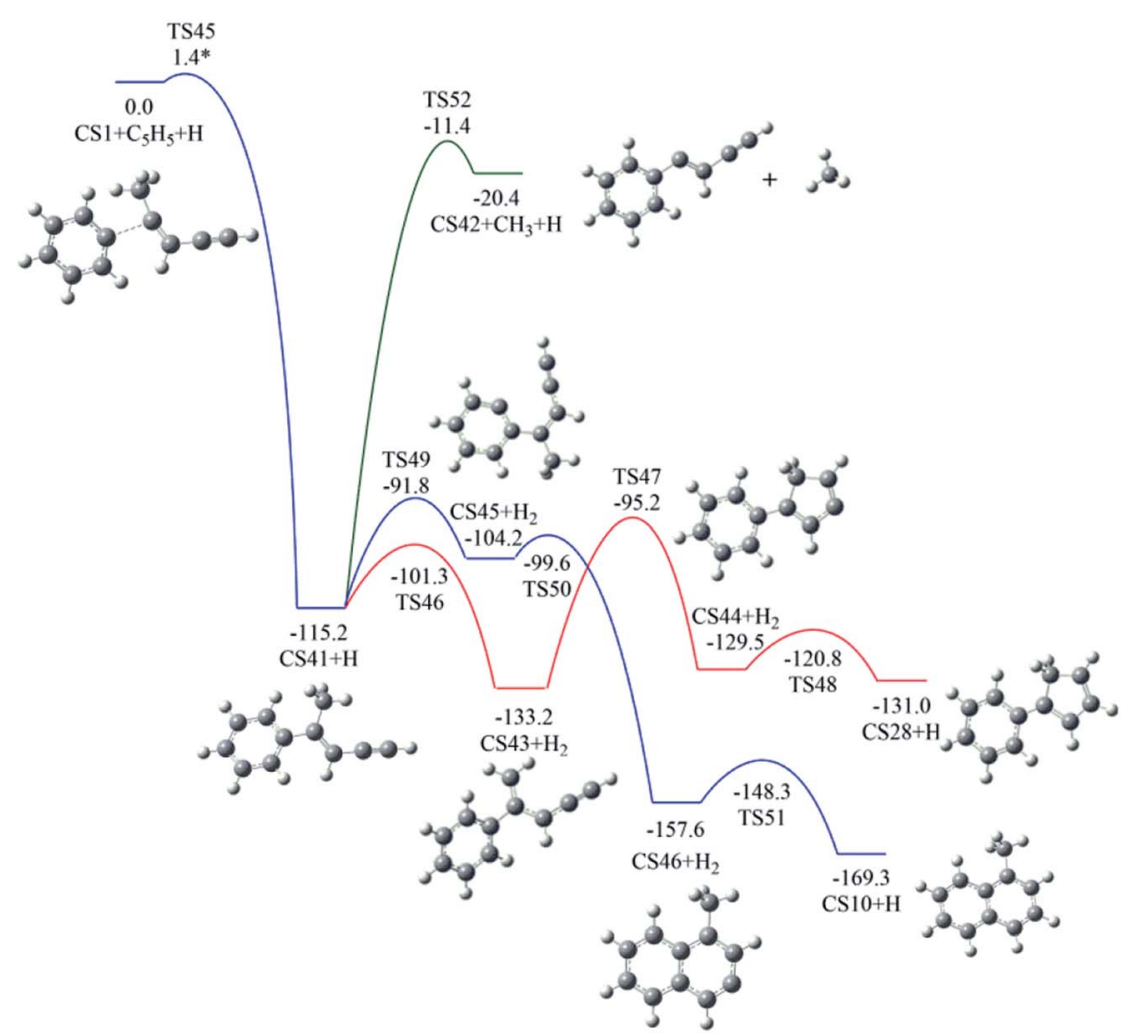

Fig. 10 Calculated potential energy surface of Pathway IV started with the reaction of $\mathrm{C}_{6} \mathrm{H}_{5}$ to the $\mathrm{C}^{4}$ position of $\mathrm{C}^{1} \mathrm{HC} \mathrm{C}^{2} \mathrm{C}^{3} \mathrm{HC} \cdot \mathrm{C}^{5} \mathrm{H}_{3}$. Relative energies are in $\mathrm{kcal} \mathrm{mol}^{-1}$. 
From the results above, it is found that the reaction of phenyl radical with cis-3-penten-1-yne at the $\mathrm{C}^{1}$ position can result in the formation of three PAHs, CS6, CS10, and CS13, and the highest barriers involved are 34.6, 36.8 and $34.9 \mathrm{kcal} \mathrm{mol}^{-1}$, respectively. These almost the same barriers indicate the formations of these three PAHs are competing each other.

\subsection{Pathway II}

As shown in Fig. 2, Pathway II refers to the reaction of phenyl radical with cis-3-penten-1-yne at the $\mathrm{C}^{2}$ position. The calculated potential energy surface along this pathway is depicted in Fig. 8. Similar to the situation in Pathway I, the initial association of $\mathrm{C}_{5} \mathrm{H}_{6}$ with cis-3-penten-1-yne at the $\mathrm{C}^{2}$ position is also a thermodynamically and kinetically favorable process, exothermic by $33.3 \mathrm{kcal} \mathrm{mol}^{-1}$ with a barrier of $7.1 \mathrm{kcal} \mathrm{mol}^{-1}$, leading to the adduct $\mathrm{CS} 14$. This adduct with the radical site at the $\mathrm{C}^{1}$ position, can evolves into five different PAHs, CS10, CS19, CS26, CS28 and CS29, along five possible channels. The diradical species in this pathway were found by using triplet spin multiplicity, and hence the calculations of diradical species contain spin-contamination.

The red channel gives CS19 via five elementary steps, involving transition states TS15-TS19. The radical site at $\mathrm{C}^{1}$ in CS14 conjugates to the benzene ring via TS15, forming CS15 (a 4membered PAH), with a barrier of $32.0 \mathrm{kcal} \mathrm{mol}^{-1}$. Subsequently, a H-dissociation process occurs via TS16 with a barrier of
$44.6 \mathrm{kcal} \mathrm{mol}^{-1}$, followed by a H-abstract reaction via TS17 with a barrier of $11.9 \mathrm{kcal} \mathrm{mol}^{-1}$, leading to CS17 with the radical site at $\mathrm{C}^{5}$ position. Then the ring closure reaction occurs via TS18 with a barrier of $38.2 \mathrm{kcal} \mathrm{mol}^{-1}$, forming the 5 -membered ring intermediate CS18. Finally, CS19 is formed via the reaction of $\mathrm{CS} 18$ with $\mathrm{H}_{2}$ with a barrier of $15.9 \mathrm{kcal} \mathrm{mol}^{-1}$. The overall energy barrier involved in this channel is $44.6 \mathrm{kcal} \mathrm{mol}^{-1}$.

The black channel in Fig. 8 corresponds to the formation of CS26, undergoing H-migration, ring closure, and $\mathrm{H}$ dissociation steps. The $\mathrm{H}$-migration from $\mathrm{C}^{5}$ to $\mathrm{C}^{1}$ proceeds via TS20 with a barrier of $10.5 \mathrm{kcal} \mathrm{mol}^{-1}$, leading to intermediate CS20. The ring closure step produces the bicyclic PAH radical, CS25, and need to overcome a barrier of $25.1 \mathrm{kcal} \mathrm{mol}^{-1}$. The final $\mathrm{H}$-dissociation reaction yields CS26,

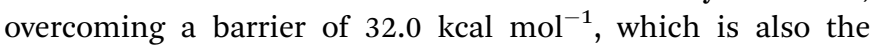
highest barrier along this channel.

Other three potential channels of the evolvement of CS20 was also explored, as shown by blue, green, and purple lines. The blue one corresponds the formation of CS10, which undergoes ring closure, $\mathrm{H}$-abstraction, ring opening and $\mathrm{H}$ addition steps. The overall barrier is calculated to be as high as $107.4 \mathrm{kcal} \mathrm{mol}^{-1}$ (the energy difference between TS23 and CS20), which is much higher than that involved in Pathway I. This result implies that CS10 is a less possible product from the reaction of phenyl radical with cis-3-penten-1-yne at the $\mathrm{C}^{2}$ position.

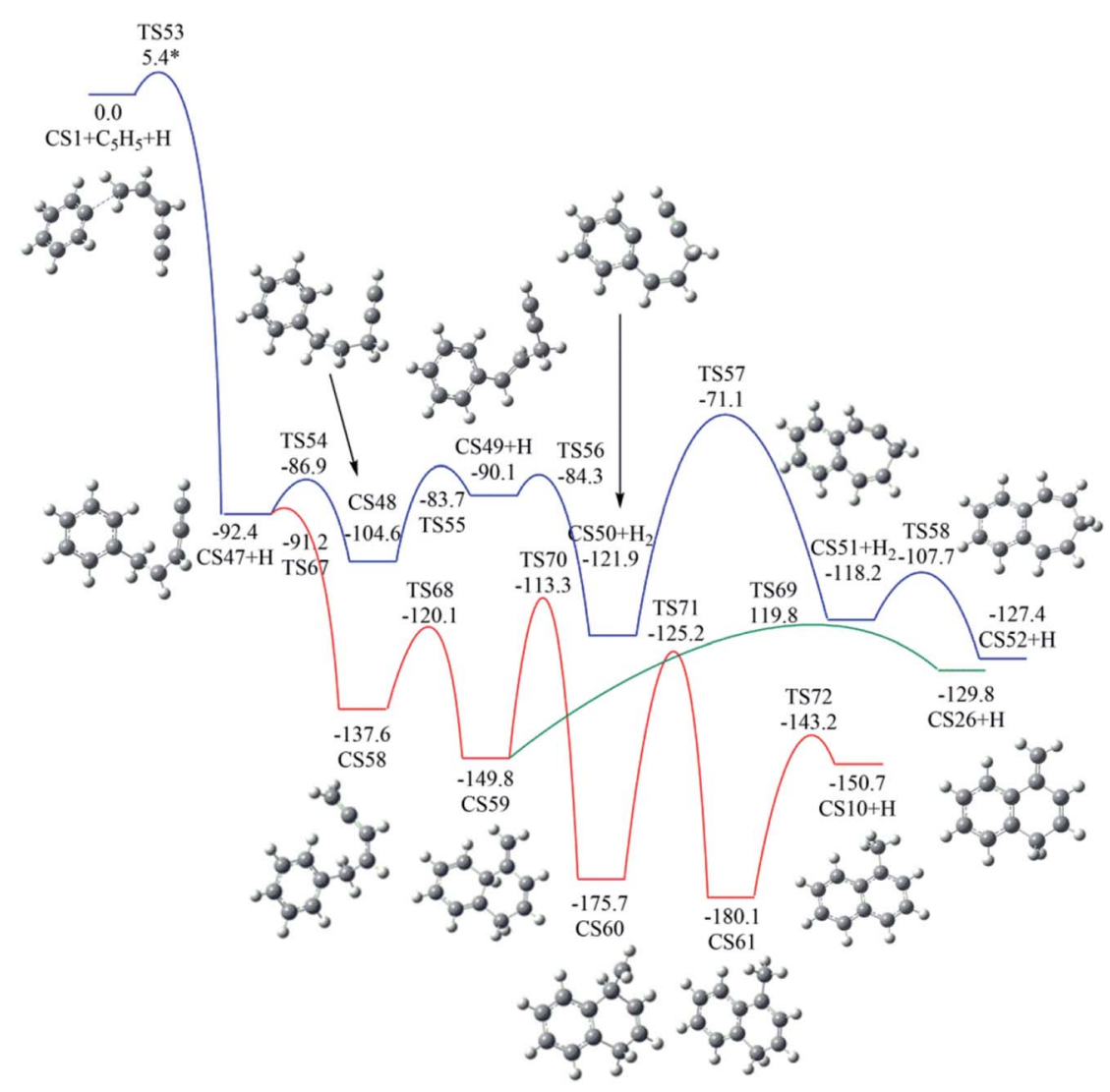

Fig. 11 Calculated potential energy surface of Pathway $\vee$ started with the reaction of $\mathrm{C}_{6} \mathrm{H}_{5}$ to the $\mathrm{C}^{5}$ position of $\mathrm{C}^{1} \mathrm{HC}^{2} \mathrm{C}^{3} \mathrm{HC}{ }^{4} \mathrm{HC}^{5} \mathrm{H}_{2} \cdot$. Relative energies are in $\mathrm{kcal} \mathrm{mol}^{-1}$. 
The green and purple channels show the formations of two PAHs (CS28 and CS29) that are structurally considered as "cyclopenta-benzene" (biphenyl with one benzene ring replaced by a cyclopenta ring). The involved overall barriers are calculated to be 62.4 and $57.5 \mathrm{kcal} \mathrm{mol}^{-1}$, respectively.

\subsection{Pathway III}

As shown in Fig. 4, Pathway III refers to the reaction of phenyl radical with the $\mathrm{C}^{3}$-radical of cis-3-penten-1-yne and $\mathrm{H}$ atom. The calculated potential energy surface is depicted in Fig. 9.

Initially, CS30 is formed via a low barrier of $2.4 \mathrm{kcal} \mathrm{mol}^{-1}$ by the direct association of phenyl radical and the $\mathrm{C}^{3}$-radical of cis- $^{-}$ 3-penten-1-yne, releasing an energy of $107.3 \mathrm{kcal} \mathrm{mol}^{-1}$. Subsequently, CS30 can evolves into different PAHs, CS10, CS13, and CS34. The blue channel in Fig. 9 shows the mechanism for the formation of CS34. The reaction occurs via $\mathrm{H}-$ abstraction, ring closure, and $\mathrm{H}$-addition steps (CS30 $\rightarrow$ CS32 $\rightarrow \mathrm{CS} 33 \rightarrow \mathrm{CS} 34)$. The $\mathrm{H}$-abstraction of CS30 leading to intermediate CS32 need to overcome an energy barrier of $19.2 \mathrm{kcal} \mathrm{mol}^{-1}$, which is also the highest energy barrier along this channel.

As shown by green, red and purple lines in Fig. 9, the formations of CS10 and CS13 involve a common, stable intermediate, CS36, which can be formed via a ring closure and a $\mathrm{H}^{-}$ addition steps (CS32 $\rightarrow$ CS35 $\rightarrow$ CS36) with an overall barrier of $15.5 \mathrm{kcal} \mathrm{mol}^{-1}$. Jasper and Hansen suggested that the ring enlargement from fulvene to benzene could be assisted by the presence of hydrogen atom. ${ }^{57}$ Fig. 9 shows the calculated results for the $\mathrm{H}$-assisted transformation from $\mathrm{CS} 36$ to $\mathrm{CS} 10$ by $\mathrm{H}^{-}$ addition, H-migration and H-loss steps (CS36 $\rightarrow$ CS37 $\rightarrow$ CS38 $\rightarrow$ CS9 $\rightarrow$ CS10). This process involves barrier of $36.9 \mathrm{kcal} \mathrm{mol}^{-1}$, which is also the overall barrier.

Instead of evolving into CS10, the intermediate CS36 can convert to CS13 undergoing intermediate CS39 with an overall barrier of $38.1 \mathrm{kcal} \mathrm{mol}^{-1}$ or undergoing intermediate CS40 with an overall of $38.1 \mathrm{kcal} \mathrm{mol}^{-1}$.

\subsection{Pathway IV}

The reaction of phenyl radical with the $\mathrm{C}^{4}$-radical of cis-3penten-1-yne is referred as Pathway IV (Fig. 5), which can results in the formation of two PAHs, CS10 and CS28. As indicated by Fig. 10, potential channel with blue lines is open for the formation of CS10 from CS41, which is formed from the initial adduct of phenyl radical with the $\mathrm{C}^{4}$-radical of cis-3-penten-1yne with very low barrier of $1.4 \mathrm{kcal} \mathrm{mol}^{-1}$, releasing an energy of $115.2 \mathrm{kcal} \mathrm{mol}^{-1}$. Along this channel, CS41 first evolves into CS45 via a $\mathrm{H}$-abstraction step. This process with a barrier of $23.4 \mathrm{kcal} \mathrm{mol}^{-1}$ is indentified as the ratedetermining step. Subsequently, the ring closure reaction leads to intermediate CS46, which undergoes a $\mathrm{H}$-abstraction reaction via TS51, producing PAH, CS10.

Another possible PAH product from the reaction of phenyl radical with the $\mathrm{C}^{4}$-radical is CS28, a "cyclopenta-benzene"-like structure. Instead of evolving into CS10, CS41 may perform $\mathrm{H}$ -

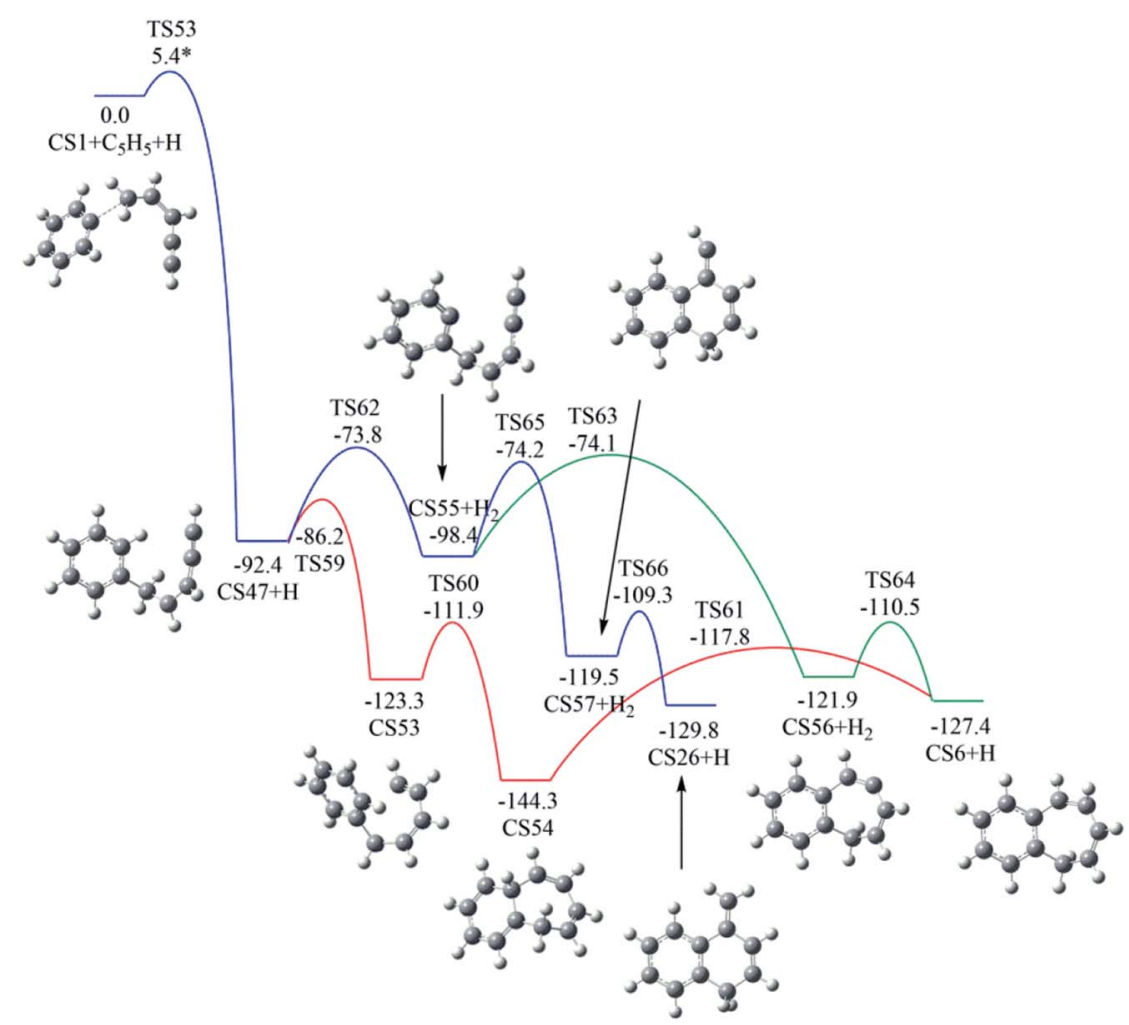

Fig. 12 Calculated potential energy surface of Pathway $V$ started with the reaction of $\mathrm{C}_{6} \mathrm{H}_{5}$ to the $\mathrm{C}^{5}$ position of $\mathrm{C}^{1} \mathrm{HC}^{2} \mathrm{C}^{3} \mathrm{HC}{ }^{4} \mathrm{HC}^{5} \mathrm{H}_{2} \cdot$. Relative energies are in $\mathrm{kcal} \mathrm{mol}^{-1}$. 
Table 1 Overall barriers for the formation of bicyclic PAHs in Pathways I-V

\begin{tabular}{|c|c|c|c|c|c|}
\hline Products & $\begin{array}{l}\text { Pathway I } \\
\left(\mathrm{kcal} \mathrm{mol}^{-1}\right)\end{array}$ & $\begin{array}{l}\text { Pathway II } \\
\left(\mathrm{kcal} \mathrm{mol}^{-1}\right)\end{array}$ & $\begin{array}{l}\text { Pathway III } \\
\left(\mathrm{kcal} \mathrm{mol}^{-1}\right)\end{array}$ & $\begin{array}{l}\text { Pathway IV } \\
\left(\text { kcal mol }^{-1}\right)\end{array}$ & $\begin{array}{l}\text { Pathway V } \\
\left(\text { kcal mol }^{-1}\right)\end{array}$ \\
\hline CS6 & 34.6 & - & - & - & 24.3 \\
\hline CS13 & 34.9 & - & 38.1 & - & - \\
\hline CS19 & - & 44.6 & - & - & - \\
\hline CS26 & - & 32.0 & - & - & 24.2 \\
\hline CS34 & - & - & 19.2 & - & - \\
\hline CS52 & - & - & - & - & 50.8 \\
\hline
\end{tabular}

abstraction, ring closure and $\mathrm{H}$-addition reactions, leading to CS28, with a barrier of $38.0 \mathrm{kcal} \mathrm{mol}^{-1}$.

\subsection{Pathway V}

As shown in Fig. 6, Pathway V refers to the reaction of phenyl radical with the $\mathrm{C}^{5}$-radical of cis-3-penten-1-yne. The present calculations locate six potential channels, leading to two sevenmembered PAHs (CS6 and CS52) and two six-membered PAHs, (CS10 and CS26).

As shown in Fig. 11, the initial association of phenyl radical with the $\mathrm{C}^{5}$-radical leads to the formation of $\mathrm{CS} 47$ with barrier of $5.4 \mathrm{kcal} \mathrm{mol}^{-1}$. Once formed, CS47 can evolve into CS52 along the blue channel via the $\mathrm{H}$-addition, $\mathrm{H}$-transfer, $\mathrm{H}$-abstraction, ring closure and $\mathrm{H}$-addition steps. The highest barrier involved is calculated to be $50.8 \mathrm{kcal} \mathrm{mol}^{-1}$.

In addition, CS47 can be converted to CS10 along the red channel. This channel consists of $\mathrm{H}$-addition, ring closure, $\mathrm{H}$ migrations and H-dissociation steps (CS47 $+\mathrm{H} \rightarrow \mathrm{CS} 58 \rightarrow$ $\mathrm{CS} 59 \rightarrow \mathrm{CS} 60 \rightarrow \mathrm{CS} 61 \rightarrow \mathrm{CS} 10+\mathrm{H}$ ). From the calculated potential energy surface (Fig. 11), rate-determining step, CS60 $\rightarrow$ CS61, involves energy barrier of $50.5 \mathrm{kcal} \mathrm{mol}^{-1}$.

Fig. 12 shows calculated potential channels for the formations of CS6 and CS26 along Pathway V. The blue channel in Fig. 12 corresponds to the formation of CS26. This channel involves $\mathrm{H}$-abstraction, ring closure and $\mathrm{H}$-addition steps. The ring closure is identified as the rate-determining step with a barrier of $24.2 \mathrm{kcal} \mathrm{mol}^{-1}$. In Fig. 11, the intermediate CS59 can convert to CS26 with an overall barrier of $30.0 \mathrm{kcal} \mathrm{mol}^{-1}$. From the calculated potential energy surface (Fig. 11 and 12), it is clear that the channel in Fig. 12 is energetically more favorable.

As indicated by red and green lines in Fig. 12, CS47 is converted to CS6 undergoing intermediates CS53 and CS54 with an overall barrier of $26.5 \mathrm{kcal} \mathrm{mol}^{-1}$ or undergoing intermediate CS55 and CS56 with an overall of $24.3 \mathrm{kcal} \mathrm{mol}^{-1}$. The minima energy pathway forms a bicyclic PAH, CS6 which is formed via the $\mathrm{H}$-abstraction, ring closure and $\mathrm{H}$-addition steps. The ring closure step is indentified as the rate-determining step with a barrier of $24.3 \mathrm{kcal} \mathrm{mol}^{-1}$. The calculated overall barriers for all final products in Pathways $\mathrm{I}-\mathrm{V}$ were listed in Table 1 in $\mathrm{kcal} \mathrm{mol}^{-1}$.

\section{Conclusions}

In this work, the reaction mechanism of PAH growth to dualring structures on $\mathrm{C}_{11} \mathrm{H}_{11}$ surface initiated by $\mathrm{C}_{6} \mathrm{H}_{5}$ with linear $\mathrm{C}_{5}$ species (cis-3-penten-1-yne) were investigated using DFT and $a b$ initio methods. Five bicyclic PAHs formation pathways are detailedly explored include reactions of phenyl radical $\left(\mathrm{C}_{6} \mathrm{H}_{5}\right)$ with cis-3-penten-1-yne (cis- $\mathrm{C}^{1} \mathrm{H} \equiv \mathrm{C}^{2}-\mathrm{C}^{3} \mathrm{H}=\mathrm{C}^{4} \mathrm{H}-\mathrm{C}^{5} \mathrm{H}_{3}$, referred to $\left.\mathrm{C}_{5} \mathrm{H}_{6}\right)$ and its three radicals $\left(\mathrm{CH} \equiv \mathrm{C}-\dot{\mathrm{C}}=\mathrm{CH}-\mathrm{CH}_{3}, \mathrm{CH} \equiv \mathrm{C}-\right.$ $\mathrm{CH}=\dot{\mathrm{C}}-\mathrm{CH}_{3}$, and cis- $\mathrm{CH} \equiv \mathrm{C}-\mathrm{CH}=\mathrm{CH}-\dot{\mathrm{C}} \mathrm{H}_{2}$, referred to the $\mathrm{C}^{3}$-, $\mathrm{C}^{4}$-, and $\mathrm{C}^{5}$-radicals with the same chemical components, $\mathrm{C}_{5} \mathrm{H}_{5}$ ). And 4-, 5-, 6- and 7- membered PAHs (referred to the species of CS6, CS10, CS13, CS19, CS26, CS28, CS29, CS34 and CS52) were designed as final products.

The results show that the initial combination of $\mathrm{C}_{6} \mathrm{H}_{5}$ with $\mathrm{C}_{5} \mathrm{H}_{6}$ or $\mathrm{C}_{5} \mathrm{H}_{5}$ is found to be highly exothermic with only minor barriers (1.4-7.1 kcal mol ${ }^{-1}$ ) in Pathways I-V, which provides a large driving force for PAH formation. The hydrogen atom is beneficial for the ring enlargement and ring formation processes.

The calculated Pathways $\mathrm{I}-\mathrm{V}$ predicate 9 potential PAHs include 4-, 5- and 7-membered rings. Among them, CS6, CS10, CS13, CS26 and CS28 could be produced from two or more pathways, CS19, CS29, CS34 and CS52 from only one pathway. At low temperature, CS6 and CS26 are more energetically favorable along Pathway V, CS10 and CS28 along Pathway IV, CS13 along Pathway I and CS34 along Pathway III. The calculated barriers for the formation of these PAHs are around 19.2$38.0 \mathrm{kcal} \mathrm{mol}^{-1}$. Hence, at low temperature, Pathway I, Pathway III, Pathway IV and Pathway V are energetically favorable for bicyclic PAHs (CS6, CS10, CS13, CS26, CS28 and CS29) formation. Considering the high temperature in various combustion flames, all above medium and even higher barriers are easily overcome. Hence, all 9 potential PAHs are easy to be produced at flame temperature. The theoretical results supplement the $\mathrm{PAH}$ formation pathway and provide some new insights to understand $\mathrm{PAH}$ growth mechanism.

\section{Conflicts of interest}

There are no conflicts to declare. 


\section{Acknowledgements}

This work is funded by the National Key R\&D Program of China (No. 2017YFC0211201, and No. 2016YFC0802801), National Natural Science Foundation of China (No. 51276132, and No. 51774221) and the 111 Project (B17034). The Key Lab of Colloid and Interface Chemistry, at Shandong University would like to be acknowledged for providing computing resources that have contributed to the research results reported within this paper.

\section{References}

1 W. M. Baird, L. A. Hooven and B. Mahadevan, Environ. Mol. Mutagen., 2005, 45, 106.

2 F. P. Perera, Science, 1997, 278, 1068.

3 H. Wang, Proc. Combust. Inst., 2011, 33, 41.

4 M. Frenklach, D. W. Clary, W. C. Gardiner and S. E. Stein, Symp. (Int.) Combust., [Proc.], 1984, 20, 887.

5 M. Frenklach and H. Wang, Proc. Combust. Inst., 1991, 23, 1559.

6 H. Wang and M. Frenklach, J. Phys. Chem., 1994, 98, 11465. 7 C. W. Bauschlicher Jr and A. Ricca, Chem. Phys. Lett., 2000, 326, 283.

8 C. W. Bauschlicher, A. Ricca and M. Rosi, Chem. Phys. Lett., 2002, 355, 159.

9 P. Ghesquière, D. Talbi and A. Karton, Chem. Phys. Lett., 2000, 595-596, 13.

10 D. S. N. Parker, R. I. Kaiser, T. P. Troy and M. Ahmed, Angew. Chem., Int. Ed., 2014, 53, 7740.

11 A. M. Mebel, Y. Georgievskii, A. W. Jasper and S. J. Kliooenstein, Proc. Combust. Inst., 2017, 36, 919.

12 V. V. Kislov, A. I. Sadovnikov and A. M. Mebel, J. Phys. Chem. A, 2013, 117, 4794.

13 A. Violi, A. D'Anna and A. D'Alessio, Chem. Eng. Sci., 1999, 54, 3433.

14 Y. Li, L. Wei, Z. Tian, B. Yang, J. Wang, T. Zhang and F. Qi, Combust. Flame, 2008, 152, 336.

15 B. Yang, Y. Li, L. Wei, C. Huang, J. Wang, Z. Tian, R. Yang, L. Sheng, Y. Zhang and F. Qi, Proc. Combust. Inst., 2007, 31, 555.

16 B. Shukla, A. Miyoshi and M. Koshi, J. Am. Soc. Mass Spectrom., 2010, 21, 534.

17 T. Yang, D. S. N. Parker, B. B. Dangi, R. I. Kaiser and A. M. Mebel, Phys. Chem. Chem. Phys., 2015, 17, 10510.

18 R. I. Kaiser, D. S. Parker, M. Goswami, F. Zhang, V. V. Kislov, A. M. Mebel, J. Aguilera-Iparraguirre and W. H. Green, Phys. Chem. Chem. Phys., 2012, 14, 720.

19 D. S. Parker, F. Zhang, Y. S. Kim, R. I. Kaiser, A. Landera and A. M. Mebel, Phys. Chem. Chem. Phys., 2012, 14, 2997.

20 D. S. N. Parker, B. B. Dangi, R. I. Kaiser, A. Jamal, M. N. Ryazantsev, K. Morokuma, A. Korte and W. Sander, J. Phys. Chem. A, 2014, 118, 2709.

21 D. S. N. Parker, F. Zhang, Y. S. Kim, R. I. Kaiser, A. Landera, V. V. Kislov, A. M. Mebel and A. G. G. M. Tielens, Proc. Natl. Acad. Sci. U. S. A., 2012, 109, 53.

22 T. Yang, L. Muzangwa, R. I. Kaiser, A. Jamal and K. Morokuma, Phys. Chem. Chem. Phys., 2015, 17, 21564.
23 R. I. Kaiser, B. B. Dangi, T. Yang, D. S. N. Parker and A. M. Mebel, J. Phys. Chem. A, 2014, 118, 6181.

24 D. S. Parker, B. B. Dangi, R. I. Kaiser, A. Jamal, M. Ryazantsev and K. Morokuma, J. Phys. Chem. A, 2014, 118, 12111.

25 T. Yang, L. Muzangwa, D. S. N. Parker, R. I. Kaiser and A. M. Mebel, Phys. Chem. Chem. Phys., 2015, 17, 530.

26 A. Raj, M. J. Al Rashidi, S. H. Chung and S. M. Sarathy, J. Phys. Chem. A, 2014, 118, 2865.

27 S. M. Lee, S. S. Yoon and S. H. Chung, Combust. Flame, 2004, 136, 493.

28 S. S. Yoon, D. H. Anh and S. H. Chung, Combust. Flame, 2008, 154, 368.

29 S. S. Yoon, S. M. Lee and S. H. Chung, Proc. Combust. Inst., 2005, 30, 1417.

30 J. Y. Hwang, W. Lee, H. G. Kang and S. H. Chung, Combust. Flame, 1998, 114, 370.

31 A. Raj, I. D. C. Prada, A. A. Amer and S. H. Chung, Combust. Flame, 2012, 159, 500.

32 F. Liu, X. He, X. Ma, Q. Zhang, M. J. Thomson, H. Guo, G. J. Smallwood, S. Shuai and J. Wang, Combust. Flame, 2011, 158, 547.

33 J. H. Choi, B. C. Choi, S. M. Lee, S. H. Chung, K. S. Jung, W. L. Jeong, S. K. Choi and S. K. Park, J. Mech. Sci. Technol., 2015, 29, 2259.

34 B. C. Choi, S. K. Choi, S. H. Chung, J. S. Kim and J. H. Choi, Int. J. Auto. Tech., 2011, 12, 183.

35 K. L. McNesby, A. W. Miziolek, T. Nguyen, F. C. Delucia, R. R. Skaggs and T. A. Litzinger, Combust. Flame, 2005, 142, 413.

36 D. H. Kim, J. A. Mulholland, D. Wang and A. Violi, J. Phys. Chem. A, 2010, 114, 12411.

37 D. Wang, A. Violi, D. H. Kim and J. A. Mulholland, J. Phys. Chem. A, 2006, 110, 4719.

38 V. V. Kislov and A. M. Mebel, J. Phys. Chem. A, 2008, 112, 700. 39 J. A. Mulholland, M. Lu and D. H. Kim, Proc. Combust. Inst., 2000, 28, 2593.

40 M. Lu and J. A. Mulholland, Chemosphere, 2004, 55, 605.

41 R. I. Kaiser, D. S. N. Parker and F. Zhang, J. Phys. Chem. A, 2012, 116, 4248.

42 N. Hansen, S. J. Klippenstein, J. A. Miller, J. Wang, T. A. Cool, M. E. Law, P. R. Westmoreland, T. Kasper and K. KohseHöinghaus, J. Phys. Chem. A, 2005, 110, 4376.

43 L. Wei, L. Yang, J. Chen, X. Wang, H. Li, Y. Zhu, L. Wen, C. Xu, J. Zhang, T. Zhu and W. Wang, Air Qual., Atmos. Health, 2015, 9, 823.

44 Y. Matsukawa, K. Ono, K. Dewa, A. Watanabe, Y. Saito, Y. Matsushita, H. Aoki, K. Era, T. Aoki and T. Yamaguchi, Combust. Flame, 2016, 167, 248.

45 B. Öktem, M. P. Tolocka, B. Zhao, H. Wang and M. V. Johnston, Combust. Flame, 2005, 142, 364.

46 A. Ciajolo, R. Barbella, A. Tregrossi and L. Bonfanti, Symp. (Int.) Combust., [Proc.], 1998, 27, 1481.

47 A. Santamaría, F. Mondragon, A. Molina, N. D. Marsh, E. G. Eddings and A. F. Sarofi, Combust. Flame, 2006, 146, 52. 48 A. D. Becke, J. Chem. Phys., 1992, 96, 2155.

49 A. D. Becke, J. Chem. Phys., 1992, 97, 9173. 50 A. D. Becke, J. Chem. Phys., 1993, 98, 5648. 
51 L. A. Curtiss, K. Raghavachari, P. C. Redfern, A. G. Baboul and J. A. Pople, Chem. Phys. Lett., 1999, 314, 101.

52 D. C. Young, Computational chemistry: a practical guide for applying techniques to real-world problems, John Wiley \& Sons Inc., 2001.

53 B. Temelso, C. D. Sherrill, R. C. Merkle and R. A. Freitas Jr, J. Phys. Chem. A, 2006, 110, 11160.

54 M. J. Frisch, G. W. Trucks, H. B. Schlegel, G. E. Scuseria, M. A. Robb, J. R. Cheeseman, G. Scalmani, V. Barone, B. Mennucci, G. A. Petersson, H. Nakatsuji, M. Caricato, X. Li, H. P. Hratchian, A. F. Izmaylov, J. Bloino, G. Zheng, J. L. Sonnenberg, M. Hada, M. Ehara, K. Toyota, R. Fukuda, J. Hasegawa, M. Ishida, T. Nakajima, Y. Honda, O. Kitao, H. Nakai, T. Vreven, J. A. Montgomery Jr, J. E. Peralta, F. Ogliaro, M. Bearpark, J. J. Heyd, E. Brothers, K. N. Kudin, V. N. Staroverov, R. Kobayashi,
J. Normand, K. Raghavachari, A. Rendell, J. C. Burant, S. S. Iyengar, J. Tomasi, M. Cossi, N. Rega, J. M. Millam, M. Klene, J. E. Knox, J. B. Cross, V. Bakken, C. Adamo, J. Jaramillo, R. Gomperts, R. E. Stratmann, O. Yazyev, A. J. Austin, R. Cammi, C. Pomelli, J. W. Ochterski, R. L. Martin, K. Morokuma, V. G. Zakrzewski, G. A. Voth, P. Salvador, J. J. Dannenberg, S. Dapprich, A. D. Daniels, O. Farkas, J. B. Foresman, J. V. Ortiz, J. Cioslowski and D. J. Fox, Gaussian 09, Revision B.01, Gaussian, Inc., Wallingford, CT, 2009.

55 B. B. Dangi, S. Maity, R. I. Kaiser and A. M. Mebel, J. Phys. Chem. A, 2013, 117, 11783.

56 M. Wei, T. Zhang, S. Li, G. Guo and D. Zhang, Can. J. Chem., 2017, 95, 816.

57 A. W. Jasper and N. Hansen, Proc. Combust. Inst., 2013, 34, 279. 